\title{
The Real of the Virtual: Critical Reflections on Web 2.0
}

\author{
Christos Boikos*, Konstantinos Moutsoulas ${ }^{* *}$, Charalambos Tsekeris ${ }^{* * *}$
}

* University of Gloucestershire, UK;

zephyrous696@hotmail.com

** University of East London, UK; moutsoulask@gmail.com

${ }_{* * *}$ Panteion University of Social and Political Sciences, Greece; tsekeris@gmail.com

\begin{abstract}
Social media, as the heart of Web 2.0, is a relatively novel theoretical notion and social phenomenon, pertaining to a long series of academic subjects, such as digital culture, virtual communication, e-democracy, technological convergence, and online interactivity. Arguably, one of the most useful tools to adequately interpret and analyze this phenomenon is Critical Theory. The present article aims to comprehensively discuss and reflexively elaborate on the complex interrelationship between Critical Theory and Web 2.0 developments. This mainly involves the historicization of the relevant concepts and the identification of crucial sociological, philosophical and interdisciplinary issues that strongly demonstrate the essential ontological complicity between the real and the virtual. In addition, the analytical emphasis on recent social movements, such as the Arab Spring, reflexively depicts the new media as critical media, a characteristic feature that somehow stands in contrast to the participation of the Internet in the circulation and accumulation of the Capital. Through contemporary Web's inherent paradoxes, it is eventually shown that the social potential of the new media can indeed be realised, so that the Internet serves the people and the public good.
\end{abstract}

Keywords: Social Media, Critical Theory, Digital Labour, Social Dynamics, Virtual Communities, Web 2.0, Arab Spring, Internet Studies

Acknowledgement: This reflection presents personal views of the authors. It is a modified version of a paper presented at the Fourth National Conference of the Hellenic Sociological Society (HSS) titled "Social Identities and Social Cohesion: Challenges and Prospects", which was held December 12-14, 2013 in Athens, Greece.

In recent years, the Internet and especially social networking platforms, such as Facebook, Twitter, MySpace, YouTube, Linkedln, Flickr, Fotolog, Digg, StumbleUpon, Hi5, Badoo, QQ (China), Vkontakte, Bebo, Skyrock, StudiVZ, Netlog, Instagram, Tuenti, and so on, have increasingly been very popular and pervasive (almost ubiquitous) in everyday life and ordinary experience. They imaginatively present a wide range of applications (for example, video sharing, photo sharing, online diary and communication, online entertainment, and information seeking), which have already become an integrated part of people's lives. These platforms and applications conventionally represent the new generation of the World Wide Web, that is, Web 2.0 or Social Web. The main purpose of this paper is to concisely describe and comprehensively discuss a progressive view of social media, based on critical social theory. ${ }^{1}$

\section{Critical Theory, Web $\mathbf{1 . 0}$ and Web 2.0}

The etymological roots of "critique" pertain to the old concept of crisis, in its original Greek sense of "judgment". Crisis is the process of questioning, cognitive or functional. The purpose of critique is thus the questioning, challenging or interrogation of behaviors, thoughts and values, in order to build up or synthesize knowledge. According to the Frankfurt School of Critical Theory, the central aim of the traditional theories of science (epistemologies) were

\footnotetext{
${ }^{1}$ On this topic, see Christian Fuchs's pioneering work (e.g. Fuchs 2014a).
} 
to merely understand, describe and interpret knowledge accounts, truth claims, or facts, without however interested in changing them.

Critical Theory was famously defined by Max Horkheimer and Theodor Adorno, the two main representatives of the Frankfurt School, who were heavily inspired by the Marxist concept of emancipation. Horkheimer and Adorno sought to create a strong analytical framework within which science would help people to see and get rid of hidden structures of oppression and exploitation, as well as to realise that economic relations are products of human work (Ingram and Simon-Ingram 1992). Critical Theory overtly opposes naturalism, instrumentalism and positivism, perceiving society as a total relational system and science as reflexively influenced by the socioeconomic structure.

Since the very beginning of the twenty-first century, there are arguably new structures that help manufacturing and dispersing information. This, of course, involves the creation and functioning of online networks and virtual communities, which are free of any central control or central restrictions, so that they significantly threat social order, as evidenced in the cases of grassroots organizations (change from below) and of the recent social movements in Egypt, Libya, and Turkey. In this way, the Internet serves as a strong subversive factor, helped by its own complexity, challenging the reproduction, accumulation and expansion of the capital and the sociopolitical status quo. That is why many contributions to discussions of the Internet and the social media (namely, Castells, Benkler, Papacharissi, and others) often tend to intensively stress new technologies' novelty, creativity, innovation, and transformative power (Fuchs 2014b, 57).

As Charalambos Tsekeris and loannis Katerelos (2014) also emphatically point out, Web 2.0 is, for better or for worse, a revolutionary paradigm in online networking and social interaction in general. However, it seems that much more (serious) academic enquiry and scholarship is needed beyond merely reinforcing the well-ingrained idea that Web 2.0 itself should be argued for in almost messianic terms. But let's first examine Web 2.0 over against its predecessor, that is, Web 1.0.

Nowadays, we refer to Web 2.0 as an evolution or maturation of the first generation of World Wide Web. Web 1.0 was developed in the period between 1992 and 2004. Initially, the first use of the Internet was, more or less, to e-mail and print. The social dimension of Web 1.0 is limited to the ability of the users to consume various products, to read websites and to acquire information or knowledge, without being able to intervene in the content (Flew 2008). In other words, most of the users were consumers of technological content, since only few had the energetic opportunity to "upload" information on the Internet (Cormode and Krishnamurthy 2008). Therefore, Web 1.0 merely pertains to the presentation/consumption of information rather than to its user-friendly creation and sharing.

It is notable that, with the rapid evolution of technology and the revolution of smart phones, we can observe changes in the distribution and sharing of information. In addition, the Internet has been transferred from the computer to our pocket, while the term "online" has nowadays nothing to do only with the computer. Technological devices connecting to the Internet have become the eyes and ears of modern applications. All data are now collected, presented and processed in real time (O'Reilly 2005). With this particular evolution of technology, the identity of the Web has substantially changed: the users have now the oppurtunity to synergetically participate in the configuration of information and the generation of technological content. In other words, we have moved from Web 1.0 to Web 2.0. At this point, it is raised the critical question on the nature, character and social dynamics of Web 2.0 (Tsekeris and Katerelos 2014).

It is almost difficult to precisely define Web 2.0, but we can say that Web 2.0 actually triggered a communication revolution, helped for the emergence of new ideas, and became a "paticipatory Web" (Fox and Madden 2006). Web 2.0 can be considered as a groundbreaking tool by which the users can freely express themselves, share feelings and information, and learn other cultures. It thus offers them the chance to have a stake in the very creation of knowledge. Each user now becomes a global citizen and is able to work, communicate and cooperate in different contexts (Jenkins et al. 2009). 
At this point, it is expedient to re-think of the main differences between Web 1.0 and Web 2.0. The crucial difference is that, in Web 2.0, the users have the opportunity to actively exchange information and become part of a community - a virtual community. Users are not passive receivers; they read various contents and concurrently take part in online networks and forums, critically commenting and elaborating on each other's account. In the era of Web 2.0 , interfaces are user-friendly and information is easily accessible. To put it differently, Web 1.0 connects computers, while Web 2.0 connects people (see Thomas 2009).

In general, Web 2.0 signifies a new generation of web services and applications based on participation, feedback, collaboration, creation and exchange of information via online communication. If we accept the above characteristics of Web 2.0, we can reach the idealistic conclusion that it is a participatory democratic means in the age of information society. But beyond idealistic or utopian conceptualizations, the very reality Web 2.0, as a key factor that determines users' daily habits and practices, poses the pressuring need of its critical appraisal. The crucial question that emerges here is whether Web 2.0 is actually radical or not. A wider sociohistorical view may possibly help us better answering it.

\section{A Historical Framework}

Some years before the public debut of the Internet, Michel Foucault perceptively formulated a set of groundbreaking theoretical approaches to social control. His contribution to the critical understanding of the way that the politics of surveillance and control actually work, arguably, had some common points with the Marxist approach with which, according to his own words, he was in fact not so familiar (Macherey 1998). Foucault's basic conclusion was that the human existence, starting with the human body, is completely subordinated to the needs of the reproduction of capital (Foucault 1963). The human body is not just the fundamental field of investment by capital, under the narrow sense of productive power, but it also becomes a field of intense ethical, ideological and political struggle, under the concepts of conscious and unconscious.

At this point, it can be said that the capitalist system takes the place of the Lacanian big Other, implicitly determining behaviour and thinking, and even pleasure, fantasies, restrictions and identifications. In this way, Foucault conceived the idea of bio-power (that is, power over life) with which he smartly defined the complete subordination of human life under the needs of the reproduction of capital. Furthermore, he emphasized the existence of specific institutions and processes acting in this framework, as well as on specific policies considered as necessary, aiming to the facilitation and prevalence of bio-power, always focused on the needs of the capital, policies which were famously named as bio-politics (Foucault 1975).

In this sense, bio-power amounts to the complete control of the human existence, acting like a big "eye", observing almost everything, something like Big Brother (Orwell) or the Panopticon (Bentham). But the univocal, vertical character of this phenomenon needs to be historically contextualized. And by analyzing it, in a historical background, as Norbert Elias did it, we can see that it is a phenomenon rather constructed at social micro-level and emerged throughout history, satisfying specific sociohistorical needs in specific sociohistorical contexts. The evolution of the productive powers (in the sense of the working powers) to powers of digital labour (see Fuchs and Sevignani 2013) has reflexively triggered the development of new social constructions for their surveillance and control, that is, e-surveillance (see Fuchs 2011).

Within the analytical framework of bio-power, the triangle of ideology, culture and politics come into the circulation of capital, either as direct commodities by which economic profits can be made, or as medium for its acceleration. In almost the same spirit, the enforcement of the model of the individual person, the so-called model of Homo Economicus, is indicative of how thinking (noesis) becomes another part of the circulation of capital. In this case, Smith and Ricardo's concept of Homo Economicus, the individualized/atomized transfer of humanism in the sphere of production and consumption, is constructed under the concept of "civil society" or "society of individuals" (societé civile, bürgerliche Gesellschaft). Marx suggested 
that the (bourgeois) State is not a part of civil society but it stands separately, above it, dominating and controlling it.

This view can be better understood under the Marxist concept of alienation, in which the basic elements are, firstly, the naive distinction between humanity and Nature, starting from the use of power over Nature, and secondly, our separation from the human itself and the social character of human labour and its products. This was the very starting point for the Frankfurt School and its reconstruction of the critical theory.

At this point, Marcuse and Deleuze's substantial contributions have to be recalled. Originally based on the Freudian concept of unconscious drives, these contributions point out that capitalism is a neurosis itself (Deleuze and Guattari 1977; Marcuse 1955). The capitalist way of production, associated with alienation, turns labour (or digital labour) from joy to coerced work, oppressing the pleasure principle (Freud) and forcing the dominance of the death principle (Freud) over the social subject, as the only way of exercising the bourgeois power, or in Foucauldian terms, of exercising the bio-power through bio-politics. In a more poetic way, Marx mentioned that communism is the dominance of the totality of desires, a type of Homo Poeticus.

\section{The Real of the Virtual}

Taking these thoughts and concepts into consideration, it can be understood that, in capitalist societies, the Internet (rather than being radical) is a fertile conservative ground for immediate profits, as well as for serving individual interests, either with the direct selling of commodities, even the Internet itself as a commodity, or as a hegemonic instrument of ideological and cultural manipulation. Therefore, the Internet is not another separate world beyond the Real, but an essentially integral component of the real world (see Tsekeris 2008).

The first stage of the evolution of the web, what is widely called Web 1.0, where information was moving in a vertical, absolutely top-down way, without any chance of creative feedback by the user, made all these very clear. Some years later, however, the creation and proliferation of alternative, freely distributed software, such as Linux, begun. In this Web 2.0 context, other kinds of online software have rapidly become spread and popular, like social media. In some extent, such developments achieved to break the absolute compliance of information to the need of the reproduction of the capital through alternative forms of new media. For example, Wikipedia was evolved by breaking the hitherto status of the "knowledge market", turning it to what it really is, a free right for everyone. However, because of the dominance of such new media, a novel kind of market emerged, which embraced wikis - that is, a market largely called "Wikinomics".

Hence, a wholly new way of profiting through free knowledge was formed. This phenomenon poses a crucial question involving how capitalist profit is pumped through a free commodity. A first answer lies in advertising: "For-profit and advertising logic makes media organisations dependent on market and commodity logic and prone to exclude voices that question these logics" (Fuchs 2014b, 69). Advertising manipulates humans' needs, as Marcuse puts it, and advances media concentration. Of course, it is quite clear that there are remarkable differences here. For instance, Google fulfills different needs for the user in comparison to Facebook, YouTube, or Wikipedia. Also, Google pumps its profit from the sites paying it in order to appear higher in Google's search line. Facebook, on the other hand, through a similar way, makes its profit through advertisement inside Facebook's network. Finally, Wikipedia pumps its profit through donations.

In addition to the above, there is the so-called click policy. According to this policy, the capitalist profit comes out from clicks that the users daily make, which, on the one hand, boost the popularity of specific sites (or specific videos in the case of YouTube's posttelevision), and on the other hand, raise the price of the site's share in the stock markets. This process feeds the argument that a significant turning point for the social media was their 
entrance in the stock markets, started during the late $90^{\prime} \mathrm{s}^{2}$. This process also partly signified the passage from Web 1.0 to the era of Web 2.0, while it triggered the emergence of a new field of economic investments, a phenomenon which Marx defined as constant revolutionization of the means of production.

However, it seems that an old-fashioned market of knowledge still exists, strictly attached to the Web 1.0 prototype. More specifically, large corporate publishing houses, in principle, do not allow free online access and free use of academic journals and new scientific knowledge in general, thus yielding high profits. In order to utilize scientific papers and books, the user is usually obliged to pay. This entails that the public profile of knowledge becomes reduced (or annihilated) and cultural production tends to get privatized and commodified. According to such a policy, knowledge renders inaccessible for the vast majority of society. The contemporary web hence loses its essential bottom-up character for the sake of knowledge-industrial economic interests and a relatively limited number of users-consumers.

In direct contrast to this capitalist logic, Fuchs and Sandoval (2013) suggest a new model that can substantially strengthen the academic public sphere and democratic access to knowledge: "Diamond open access (DOA) publishing is the opportunity to reclaim academic commons. It can realise the true essence of academia as a communication system that produces and communicates academic knowledge as a commons in an open process [...] Diamond open access (DOA) stands in the interests of both academic workers and publishing workers. The academic publishing houses' oligopoly profits are based on the exploitation of academic workers' free labour and publishing workers' paid labour" (Fuchs and Sandoval 2013, 441).

This genuinely re-establishes scientific knowledge as a common good and as part of a whole academic communication process, openly acknowledging the public's right to inform itself. In parallel, urgently needed is the strengthening of the valuable authority of critical and high-quality media, including independent media, investigative journalism, and public service media. These have to serve as safeguards for press freedom and the freedoms of expression, speech, information and opinion, over against corporate and state control of the media ${ }^{3}$.

In order to effectively save new media from recursive corporate and state control, turning them into truly social media, we rather need media reforms "for establishing a social media sphere that transcends particularistic control and represents the public interest so that the social potential of the media can be realised. Public service social media could overcome the Internet's antagonisms and serve the people. Social media is possible. A public service Internet is possible" (Fuchs 2014b, 97).

Reforms should always keep in mind that the virtual world is not another (ontologically different) world, stranger or unfamiliar to the Real, but it is intimately intertwined to the wider socio-political and historical framework. At the same time, the Virtual (or the virtual Real) reflexively influences this framework within a kind of double hermeneutics. Recent examples of this double hermeneutics pertain to the active role of social media in the Arab Spring ${ }^{4}$, the mass popular insurrections in Turkey ${ }^{5}$, the grassroots protest movement of Los Indignados (the "Outraged") in Spain and Portugal ${ }^{6}$, the virtual activist/hacktivist movement of Anonymous $^{7}$, and many more. In particular, the social upheavals and the Jasmine Revolution in

\footnotetext{
${ }^{2}$ Through stock markets, "Facebook tries to attract investors and to thereby increase its capital base and operations [...] Its public listing as stock market company has made Facebook definitely more prone to crisis and therefore more inclined to extend and intensify the exploitation of users" (Fuchs and Sevignani 2013, 288).

${ }^{3}$ Typical cases of direct media control are the regimes with Internet restrictions, as in Iran, China, and North Korea. The case of Turkey can also be added, as Erdogan's government has attempted to apply certain reforms, based on Muslim ethics, by restricting Internet use (quite recently, by blocking Twitter across the country). The Turkish government, under the experience of the Arab Spring, used to organize its own self-defence by shutting down servers, imposing censorship and disparaging the new media as devilish corruptors of the Turkish youth. However, Erdogan's attempts proved to be unable to control new media dynamics.

${ }^{4}$ See http://en.wikipedia.org/wiki/Arab_Spring

${ }^{5}$ See http://en.wikipedia.org/wiki/2013\%E2\%80\%9314 protests in Turkey

${ }^{6}$ See http://en.wikipedia.org/wiki/2011\%E2\%80\%9312 Spanish_protests

${ }^{7}$ See http://en.wikipedia.org/wiki/Anonymous_\%28group\%29
} 
Tunisia $^{8}$, resulting in the collapse of Ben Ali's government, highlighted the role of blogs (see Tsekeris 2009) and serve as the starting point for a whole anti-authoritarian and anti-poverty popular movement throughout the Arab world (Libya, Egypt, Syria, Iran, Yemen, Algeria, Morocco, Jordan, Bahrain, Syria, Kuwait, etc).

For instance, Figure 1 vividly shows the profound social dynamics of the Egyptian revolution in cyberspace, at the time of the announcement of Mubarak's resignation on February 11,2011 . It is demonstrable that the few nodes (i.e. Twitter users) and edges, sparse in time, have rapidly been increased right after the announcement. This is the outcome of the dynamic network visualization of the boom of retweets with the use of Gephi open-source software for analyzing large networks.

Figure 1: A Twitter public sphere - The dynamic network of retweets, at the time of the announcement of Mubarak's resignation (data's source: http://gephi.org/2011/the-egyptianrevolution-on-twitter, accessed on April 15, 2014)

Furthermore, in the USA and Greece, social media have drastically facilitated the selforganisation of massive, grassroots social movements, such as the protest movement Occupy Wall Street (USA) $)^{9}$ and the so-called "square" movement of Aganaktismenoi (Greece), also known as the Indignant Citizens Movement ${ }^{10}$. In addition, the profound role of the new media in self-organized social mobilizations, civil disobedience, and collective action has arguably appeared earlier in another uprising in Greece, the intensive riots during December $2008^{11}$.

\section{Concluding Remarks}

Those global sociopolitical developments indeed depict the Internet of Web 2.0, paradigmatised by social media or online social networking platforms, as "potentially disrupting, undermining or otherwise threatening the established way of doing things in society...Whatever people are doing in [new] media, it clearly has become a threat to the establishment - even when it involves people expressing their unbridled embrace of the commodification of their

\footnotetext{
${ }^{8}$ See http://en.wikipedia.org/wiki/Tunisian_Revolution

${ }^{9}$ See http://en.wikipedia.org/wiki/Occupy Wall_Street

${ }^{10}$ See http://en.wikipedia.org/wiki/2010\%E2\%80\%9312 Greek protests

${ }^{11}$ See $\underline{\text { http://en.wikipedia.org/wiki/2008_Greek_riots }}$
} 
deepest intimacies through commercial platforms for the public exchange of private information" (Deuze 2012). This undoubtedly involves the ongoing dynamic interaction and intraaction between Web 2.0 and social life, or between the virtual and the real, which renders our contemporary reality (irreducibly) mutable and fragile as never before (Tsekeris and Katerelos 2012, 245).

The great paradox of contemporary media mainly pertains to the increasing intriguing tension between the bottom-up radical potential and the top-down regulatory dynamics. Huge power asymmetries still flourish, while the emergent freedom of self-expression thrives in the vast and irreducible complexity of daily Internet practices ${ }^{12}$. Social media seem to walk on a very thin line between emancipation and manipulation, liberation and control or, in other words, between e-democracy and e-dictatorship. In Gramscian terms, the non-linear play of hegemony in the chaotic virtual worlds cannot be forecasted, controlled, or predicted; it may be lost or won, but never permanently ${ }^{13}$.

Technological progress cannot advance society and the human condition unless we courageously set into motion the subversive dynamics of an everyday practice-oriented Virtualpolitik (Losh 2005). It rather seems that "the only alternative to exit the Internet crisis and exploitation economy is to exit from digital labour, to overcome alienation, to substitute the logic of capital by the logic of the commons and to transform digital labour into playful digital work" (Fuchs and Sevignani 2013, 288-289). What is therefore immediately needed is a true social media revolution that makes "social media" truly and fully social (Fuchs and Sevignani 2013; Fuchs 2014a). Arguably, critical social theory can help us better understand this project and set it forth.

\section{References}

Cormode, Graham and Balachander Krishnamurthy. 2008. Key differences between Web 1.0 and Web 2.0. First Monday 13 (6): 1-30.

Deleuze, Gilles and Felix Guattari. 1977. Anti-Oedipus: Capitalism and Schizophrenia. New York: Viking Press. Deuze, Mark. 2012. Media Life Is A Threat To Social Order. Culture Digitally // Examining Contemporary Cultural Production. http://culturedigitally.org/2012/01/media-life-is-a-threat-to-social-order (accessed on April 16, 2014)

Flew, Terry. 2008. New Media: An Introduction. Melbourne: Oxford University Press.

Foucault, Michel. 1963. The birth of the clinic: An archaeology of medical perception. London: Routledge. Foucault, Michel. 1975. Discipline and punish: The birth of the prison. London: Penguin.

Fox, Susannah and Mary Madden. 2006. Riding the waves of "Web 2.0". Pew Research Internet Project. http://www.pewInternet.org/2006/10/05/riding-the-waves-of-web-2-0/ (accessed on April 11, 2014)

Fuchs, Christian. 2011. New Media, Web 2.0 and Surveillance. Sociology Compass 5 (2): 134-147.

Fuchs, Christian. 2014a. Social Media: A Critical Introduction. London: Sage.

Fuchs, Christian. 2014b. Social Media and the Public Sphere. tripleC: Communication, Capitalism \& Critique 12 (1): $57-101$.

Fuchs, Christian and Marisol Sandoval. 2013. The Diamond Model of Open Access Publishing: Why Policy Makers, Scholars, Universities, Libraries, Labour Unions and the Publishing World Need to Take NonCommercial, Non-Profit Open Access Serious.tripleC: Communication, Capitalism \& Critique 11 (2): 428 443.

Fuchs, Christian and Sebastian Sevignani. 2013. What Is Digital Labour? What Is Digital Work? What's Their Difference? And Why Do These Questions Matter for Understanding Social Media? tripleC: Communication, Capitalism \& Critique 11 (2): 237-293.

\footnotetext{
${ }^{12}$ Christian Fuchs also describes this persistent paradox: "Contemporary activists create public spaces of protest and make use of social media and face-to-face communication, online digital and offline non-digital media, in order to voice their political demands. At the same time they are confronted with the threat that both social media corporations and state institutions control corporate social media and thereby have the power to directly or algorithmically control political movements' internal and public communication capabilities. Civil society is facing an antagonism between networked protest communication that creates political public spheres online and offline and the particularistic corporate and state control of social media that limits, feudalises and colonises these public spheres" (Fuchs 2014b, 89).

${ }^{13}$ In general, virtual worlds are complex dynamic systems that have emergent and self-organizing properties under far-from-equilibrium conditions, that is, conditions near the boundary of chaos (see Tsekeris and Katerelos 2012).
} 
Ingram, David and Julia Simon-Ingram. 1992. Critical Theory: The Essential Readings. St. Paul, MN: Paragon House.

Jenkins, Henry, Purushotma, Ravi, Weigel, Margaret, Clinton, Katie and Alice Robison. 2009. Confronting the Challenges of Participatory Culture: Media Education for the 21 st Century. Cambridge, MA: MIT Press.

Losh, Elizabeth. 2005. Virtualpolitik: Obstacles to Building Virtual Communities in Traditional Institutions of Knowledge. Center for Studies in Higher Education. Paper CSHE-9-05. http://repositories.cdlib.org/cshe/CSHE-9-05 (accessed on April 17, 2014)

Macherey, Pierre. 1998. In a Materialist Way: Selected Essays. London: Verso.

Marcuse, Herbert. 1955. Eros and Civilization, A philosophical inquiry into Freud. Boston: Beacon Press.

O'Reilly, Tim. 2005. What is Web 2.0: Design Patterns and Buisness Models for the Next Generation of Software. http://oreilly.com/web2/archive/what-is-web-20.html (accessed on April 10, 2014)

Thomas, Michael. 2009. Handbook of Research on Web 2.0 and Second Language Learning. Hershey, PA: Information Science Reference.

Tsekeris, Charalambos. 2008. Thoughts on the Nature of the Virtual. Ubiquity 9 (28). http://ubiquity.acm.org/article.cfm?id=1399626 (accessed on April 13, 2014)

Tsekeris, Charalambos. 2009. Blogging as revolutionary politics. Research Journal of Social Sciences 4: 51-54.

Tsekeris, Charalambos and Ioannis Katerelos. 2012. Web 2.0, complex networks and social dynamics. Contemporary Social Science 7 (3): 233-246.

Tsekeris, Charalambos and Ioannis Katerelos. 2014. The Social Dynamics of Web 2.0: Interdisciplinary Perspectives. London: Routledge.

\section{About the Authors}

\section{Christos Boikos}

holds a bachelor's degree in Psychology from the University of Gloucestershire (Cheltenham, UK). He is now cooperating with the Centre of Psychoanalytic Research in Athens, with emphasis on the Lacanian orientation of psychoanalysis (www.centrerepsy.gr/).

Konstantinos Moutsoulas

has studied Psychology at the School of Natural \& Social Sciences, University of Gloucestershire (Cheltenham, UK). He is currently completing his postgraduate studies for a Master degree in Clinical and Community Psychology at the University of East London, UK. Results of his dissertational research (Big Five and Schema Therapy: A new perspective on facebook use) have been presented during an academic seminar for the prevention and treatment of high-risk online behavior, hosted by Hellenic Association for the Study of Internet Addiction Disorder (Athens 2013).

Charalambos Tsekeris

graduated with Distinction from the Department of Human Sciences at Brunel University (West London, UK) and earned his doctoral degree in Reflexivity from the Department of Sociology at Panteion University of Social and Political Sciences (Athens, Greece). He is Visitor at the Hellenic Naval Staff and Command College and Senior Researcher at the Laboratory of Virtual Reality, Internet Research \& E-Learning (Department of Psychology, Panteion University). He has been Associate Lecturer at Anglia Ruskin University, University of Wales, University of Gloucestershire, and University of East London. He has also taught at the University of Piraeus and the National and Kapodistrian University of Athens, and given numerous invited lectures and papers in scientific meetings and conferences. His current academic and research interests involve relational approaches in the social science, reflexivity and the self, methodology and metatheory, social epistemology and psychosocial studies, theoretical and philosophical psychology, chaos theory and the social dynamics of Web 2.0, virtual communities, human complex systems and social networks. He is the co-editor of the book The Social Dynamics of Web 2.0 (Routledge 2014). https://sites.google.com/site/tsekeris/ 